\title{
INFLUÊNCIA DE EFLUENTES TÊXTEIS E ALIMENTÍCIOS SOBRE O METABOLISMO E PROPRIEDADES FÍSICAS E QUÍMICAS DO RIO PIAUITINGA (SERGIPE)
}

\author{
Regina Célia Bastos de Andrade \\ Departamento de Química - Universidade Federal de Sergipe - Cidade Universitária - Jardim Rosa Elze - 49100-000 - \\ São Cristóvão - SE \\ Marcelo Friederichs Landim de Souza \\ Núcleo de Estudos do Semi-Árido - Universidade Federal de Sergipe - Cidade Universitária - Jardim Rosa Elze - 49100-000 - \\ São Cristóvão - SE \\ Departamento de Geoquímica - Universidade Federal Fluminense - Outeiro de São João Batista, s/nº - 24020-007 - Niterói - RJ \\ Erminda da Conceição Guerreiro Couto \\ Departamento de Biologia - Universidade Federal de Sergipe - Cidade Universitária - Jardim Rosa Elze - 49100-000 - \\ São Cristóvão, SE \\ Recebido em 9/6/97; aceito em 7/11/97

\begin{abstract}
EFFECTS OF TEXTILE AND FOOD INDUSTRIES WASTEWATERS IN THE PHYSICO - CHEMICAL PROPERTIES AND METABOLISM OF PIAUITINGA RIVER (NORTHERN, BRAZIL). Metabolic rates were determined by dissolved oxigen changes in light and dark bottles, filled with river water and after input of mixed effluent concentrations. In another experiment, dissolved inorganic nutrients, chlorophyll- $\alpha$ and other physico-chemical parameters were analyzed. Water column showed higher decomposition than production rates. Waste inputs increased primary production rates, but in higher concentrations forced the system to heterotrophy. The natural richness of macrophytes and macroalgae could be limiting the phytoplanktonic production by phosphorus assimilation. Observation of the nitrogenated inorganic nutrients suggest that the natural pelagic system is directed to nitrification. Mixed waste input inverted this trend, toward denitrification.
\end{abstract}

Keywords: industrial effluents; metabolic rates; dissolved inorganic nutrients.

\section{INTRODUÇÃO}

É bem estabelecida a noção de que o aporte de esgotos e rejeitos industriais promove alterações significativas nas características físico-químicas dos ambientes aquáticos ${ }^{1,2}$. Entretanto, o impacto dos diversos tipos de efluentes, assim como sua ação conjunta sobre os processos biogeoquímicos que ocorrem em cada compartimento ainda são objeto de estudo ${ }^{3,4,5}$.

Os rejeitos de indústrias alimentícias, além do forte caráter ácido ou básico ${ }^{6}$, apresentam grande concentração de sólidos orgânicos em suspensão ${ }^{7}$. Esta elevada carga orgânica provoca em muitos casos depleção do oxigênio dissolvido e modificações na comunidade biológica $^{8,9}$. Os efluentes de indústrias têxteis, possuem altas concentrações de álcalis, carboidratos, proteinas, além de corantes contendo metais pesados ${ }^{10}$. Em grandes concentrações, os metais pesados possuem ação tóxica sobre os microoorganismos responsáveis pela decomposição da matéria orgânica, reduzindo a capacidade auto-depurativa dos corpos aquáticos ${ }^{3}$.

Este trabalho teve como objetivo avaliar o efeito do lançamento de efluentes têxteis e alimentícios in natura sobre o metabolismo (fotossíntese/respiração), biomassa primária e dinâmica de nutrientes inorgânicos dissolvidos na coluna d'água de um ambiente lótico.

\section{ÁREA DE ESTUDO}

O município de Estância é drenado pela bacia hidrográfica do rio Piauí. O Rio Piauitinga é o seu afluente de maior vazão, sendo responsável por todo o fornecimento díágua para a região. Além do lançamento de esgotos domésticos do município, as indústrias têxteis, de processamento de sucos e alimentícias localizadas às

E-mail: minda@ufs.br margens do Rio Piauitinga, utilizam suas águas em suas etapas industriais, despejando seus resíduos líquidos e particulados neste ambiente aquático. As populações ribeirinhas à jusante dos despejos utilizam suas águas para consumo, contato primário e pesca.

Este trabalho foi realizado na represa de captação de água deste município, marcada pela presença de macrófitas emergentes (domínio de Eleocharis interstintica - Cyperaceae), submersas (Myriophyllum sp) e macroalgas (principalmente Chara sp e Enteromorpha spp) aderidas principalmente às paredes da represa, além de cianobactérias.

\section{PARTE EXPERIMENTAL}

Foram conduzidos dois tipos de experimentos de campo, na base da represa de captação d'água do município de Estância-SE. $\mathrm{O}$ primeiro para avaliar o impacto dos efluentes em conjunto na fixação fotossintética de carbono inorgânico e na degradação microbiana de carbono orgânico (produção primária e decomposição pelágica). O segundo, para verificar a influência dos efluentes, em três concentrações distintas, nas características físico-químicas da coluna d'água ${ }^{8}$. Para estes experimentos, coletaram-se os efluentes industriais diretamente do cano de descarga das empresas escolhidas. Para obtenção do efluente composto, homogenizaram-se proporções iguais dos mesmos.

Foi realizado um experimento de incubação in situ, em 4 frascos de DBO. Água coletada acima da represa de Estância com o auxílio de garrafa de van Dorn foi usada como controle $\left(\mathrm{C}_{0}\right)$. Outros três frascos foram preenchidos com esta água, sendo adicionadas quantidades crescentes de efluentes, com o uso de uma seringa. As adições foram calculadas para fornecer as seguintes proporções da mistura água/efluentes: $\mathrm{C}_{1}=19: 1, \mathrm{C}_{2}=9: 1$ e $\mathrm{C}_{3}$ $=1: 1$. O mesmo procedimento foi repetido utilizando-se frascos escuros de igual capacidade, para avaliar-se o consumo de oxigênio por processos de decomposição. A concentração de oxigênio 
dissolvido (OD) foi determinada por iodometria de acordo com Grasshoff et al. ${ }^{12}$, no tempo zero e após três horas.

$\mathrm{O}$ segundo experimento foi realizado com bolsas de polietileno transparentes, com tampa rosqueada, com capacidade de aproximadamente $20 \mathrm{~L}$. Foram seguidas as mesmas condições de proporcionalidade utilizadas durante o primeiro experimento. Foram efetuadas quatro amostragens, cada uma com intervalo de tempo de duas horas, do tempo zero $\left(\mathrm{T}_{0}\right)$ ao tempo três $\left(\mathrm{T}_{3}\right)$, totalizando seis horas de incubação. As amostras foram recolhidas com o auxílio de uma seringa de $60 \mathrm{~mL}$. Para cada amostra foi determinado in situ o $\mathrm{pH}$, a condutividade e a temperatura.

No laboratório, as amostras foram filtradas em filtros de fibra de vidro tipo $\mathrm{GF} / \mathrm{C}$ (previamente calcinados à $450^{\circ} \mathrm{C}$ ), para a análise de carbono orgânico particulado através de digestão com mistura $\mathrm{H}_{2} \mathrm{SO}_{4} / \mathrm{K}_{2} \mathrm{Cr}_{2} \mathrm{O}_{7}$ e leitura espectrofotométrica do dicromato reduzido ${ }^{13}$. A clorofila foi determinada em filtro de fibra de vidro $(\mathrm{GF} / \mathrm{C})$ por método espectrofotométrico tricromático $^{13}$, utilizando-se extração com acetona a $90 \%$ v.v..

Após a filtração, alíquotas foram reservadas para análise de fosfato, nitrato, nitrito e amônia $\left(\mathrm{NH}_{3} / \mathrm{NH}_{4}{ }^{+}\right)$pelos métodos espectrofotométricos descritos em Grasshoff et al. ${ }^{12}$.

\section{RESULTADOS E DISCUSSÃO}

\section{Produção Primária e Decomposição Pelágica}

Os resultados das medidas de produção primária (Fig. 1) mostram um ambiente heterotrófico, com respiração bruta e líquida $\left(0,12\right.$ e 0,19 mmoles de $\mathrm{O}_{2} \cdot \mathrm{h}^{-1}$, respectivamente). A adição de duas concentrações crescentes do efluente composto (19:1 e 9:1) promove um aumento nas taxas de produção líquida $\left(0,19\right.$ e 0,27 mmoles de $\mathrm{O}_{2} \cdot \mathrm{h}^{-1}$, respectivamente), provavelmente devido ao aumento na disponibilidade de nutrientes. Este aumento promove a transição do sistema incubado de uma situação de heterotrofia (decomposição) para autotrofia (produção) líquida. Em uma concentração maior (1:1) foi observada respiração líquida de 0,08 mmoles de $\mathrm{O}_{2} \cdot \mathrm{h}^{-1}$. O efeito tóxico do efluente em maior concentração pode ter promovido uma inibição da atividade fotossintética ou, simplesmente, haver sido atingido o limite para o aumento das taxas de produção da comunidade fitoplanctônica por aumento da concentração de nutrientes. Shukla et al. ${ }^{4}$ observaram que a presença de pigmento têxtil em altas concentrações provocou uma diminuição da produção primária e biomassa fitoplanctônica. No entanto, os resultados obtidos para as taxas de produção bruta não sugerem acentuada ação tóxica ao fitoplancton. Ao mesmo tempo, o incremento no aporte de matéria orgânica causa o aumento da demanda de $\mathrm{O}_{2}$ para a respiração.

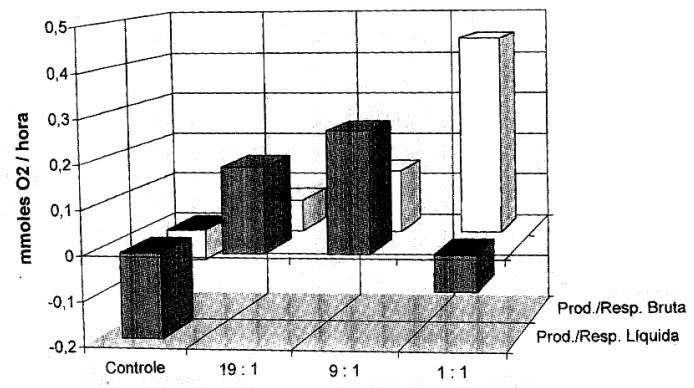

Figura 1. Taxas metabólicas brutas e líquidas obtidas no experimento de incubação em frascos de DBO (produção primária x decomposição pelágica). Valores positivos $=$ produção; valores negativos $=$ respiração .

A entrada do efluente composto nas três concentrações promoveu o incremento das taxas de produção primária bruta. Este resultado concorda, parcialmente, com o obtido por Lewitus \& $\mathrm{Kana}^{5}$, que observaram que em certas espécies de fitoplâncton a adição de substrato orgânico dissolvido (glicose) promove um aumento na pigmentação e fotossíntese, acompanhado por um incremento nas taxas de respiração brutas. Considerandose as taxas líquidas obtidas em nosso experimento, observa-se que o maior aumento da concentração do substrato orgânico promove um retorno à heterotrofia.

\section{Influência dos Efluentes nas Características Físico-químicas}

O efluente composto é uma grande fonte de carbono orgânico (95 mg C $\mathrm{morg}_{\text {. }} \mathrm{L}^{-1}$ ). Apesar do $\mathrm{pH}$ baixo do efluente da indústria de amido, predominou o $\mathrm{pH}$ elevado da indústria têxtil no composto (Tabela 1). Os resultados para clorofila- $\alpha$, no controle, demostram um compartimento pelágico muito pobre em termos de biomassa fitoplanctônica, bem como um incremento da mesma ao longo das incubações (Fig. 2). Este fato seria função da exclusão do sistema dos principais consumidores de nutrientes inorgânicos dissolvidos daquele ambiente. As macrófitas emergentes e submersas em condições naturais agiriam como verdadeiras bombas de nutrientes, principalmente de fosfato ${ }^{14}$. Com esta maior disponibilidade de nutrientes haveria um aumento da biomassa fitoplanctônica no ambiente. Os demais dados evidenciam picos de biomassa com posterior declínio no sistema.

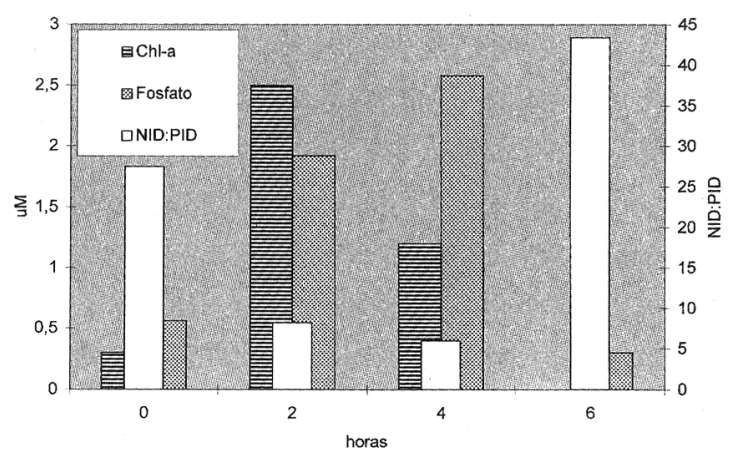

Figura 2. Variação da concentração de clorofila- $\alpha$, fosfato e da relação entre nitrogênio e fósforo inorgânico dissolvido (NID:PID) ao longo do tempo, no controle do experimento com bolsas de polietileno.

Foram calculadas as concentrações teóricas de diluição para cada experimento de incubação, em função da concentração de cada nutriente na água e no efluente composto (Tabela 2). Observou-se que as concentrações obtidas para os nutrientes inorgânicos dissolvidos, não correspondem ao esperado pela simples diluição. Isto evidenciou a presença de processos químicos e/ou biológicos, ocorridos durante a mistura com a água do sistema natural. Esta alteração nas concentrações de nutrientes também se verificou durante a preparação do efluente misto (Tabela 1), produzindo concentrações inferiores (nitrito e amônia) e superiores (fosfato e nitrato) que às esperadas em uma mistura $1: 1: 1$. O fosfato no controle, apresenta um padrão de incremento em sua concentração até o tempo 2 (Fig. 2). Isto poderia ser explicado pela decomposição de parte do material particulado e pela ausência de assimilação por macrófitas e macroalgas, no experimento.

$\mathrm{O}$ incremento de fosfato com relação às concentrações teóricas de diluição poderia ser devido à lise celular, em função da presença do efluente. Este altera o $\mathrm{pH}$ do meio, elevando-o de 7,5 a > 10,0, e aumenta o teor de sais, incrementando a condutividade de 510 para $>1330 \mu \mathrm{S} . \mathrm{cm}^{-1}$, ocasionando assim o rompimento da parede celular fitoplanctônica e bacteriana. Outra possibilidade é a alteração da partição do 
Tabela 1. Caracterização físico-química dos efluentes. Valores em negrito expressam resultados notáveis e/ou não esperados (explicação no texto).

\begin{tabular}{|c|c|c|c|c|c|c|c|}
\hline Efluente & $\mathrm{pH}$ & $\begin{array}{l}\text { Condutiv. } \\
\mu \mathrm{S} . \mathrm{cm}^{-1}\end{array}$ & $\begin{array}{c}\mathrm{PO}_{4^{-}}{ }^{3} \\
\mu \mathrm{mol} . \mathrm{L}^{-1}\end{array}$ & $\begin{array}{c}\mathrm{NO}_{2}^{-} \\
\mu \mathrm{mol} . \mathrm{L}^{-1}\end{array}$ & $\begin{array}{c}\mathrm{NO}_{3}^{-} \\
\mu \mathrm{mol} . \mathrm{L}^{-1}\end{array}$ & $\begin{array}{l}\mathrm{NH}_{3} / \mathrm{NH}_{4}^{+} \\
\mu \mathrm{mol} . \mathrm{L}^{-1}\end{array}$ & $\begin{array}{c}\text { NID } \\
\mu \mathrm{mol} . \mathrm{L}^{-1}\end{array}$ \\
\hline Amido & 5,50 & $>1999$ & 20,3 & 0,63 & 5,2 & 18,0 & 23,8 \\
\hline Frutas & 7,43 & 630 & 4,4 & 0,98 & 10,7 & 318,8 & 330,5 \\
\hline Têxtil & 12,56 & $>1999$ & 2,2 & 1,20 & 73,8 & 65,3 & 140,3 \\
\hline Composto & 12,28 & > 1999 & 3,4 & 1,57 & 18,8 & 221,6 & 242,0 \\
\hline Diluição $^{\mathrm{a}}$ & - & - & 9,0 & 0,94 & 29,9 & 134,0 & 164,9 \\
\hline
\end{tabular}

${ }^{a}$ Calculado pela média da concentração dos três tipos de efluentes

Tabela 2. Concentração de nutrientes inorgânicos dissolvidos nas incubações. Valores em negrito expressam resultados notáveis e/ou não esperados (explicação no texto).

\begin{tabular}{crcccc}
\hline Amostra & \multicolumn{1}{c}{ Hora } & $\mathrm{PO}_{4}{ }^{3-}$ & $\mathrm{NH}_{3} / \mathrm{NH}_{4}{ }^{+}$ & $\mathrm{NO}_{2}{ }^{-}$ & $\mathrm{NO}_{3}$ \\
\hline Teórica $^{\mathrm{a}}$ & \multicolumn{1}{c}{$\mathrm{N}$} & - & - & - & - \\
$\mathrm{T}_{0} \mathrm{C}_{0}$ & $9: 30$ & 0,56 & 0,85 & 1,83 & 11,7 \\
$\mathrm{~T}_{1} \mathrm{C}_{0}$ & $11: 35$ & 1,92 & 3,16 & 1,83 & 12,0 \\
$\mathrm{~T}_{2} \mathrm{C}_{0}$ & $13: 35$ & 2,58 & 0,91 & 1,27 & 12,1 \\
$\mathrm{~T}_{3} \mathrm{C}_{0}$ & $15: 35$ & 0,30 & 1,10 & 0,94 & 10,1 \\
$\mathrm{Teórica}^{\mathrm{a}}$ & & $\mathbf{0 , 5 9}$ & $\mathbf{3 , 0 6}$ & 1,83 & 11,7 \\
$\mathrm{~T}_{0} \mathrm{C}_{1}$ & $9: 30$ & $\mathbf{4 , 7 3}$ & $\mathbf{2 , 5 4}$ & 1,69 & 11,1 \\
$\mathrm{~T}_{1} \mathrm{C}_{1}$ & $11: 35$ & 5,66 & 2,16 & 2,02 & 9,42 \\
$\mathrm{~T}_{2} \mathrm{C}_{1}$ & $13: 35$ & 5,06 & 1,91 & 1,28 & 9,99 \\
$\mathrm{~T}_{3} \mathrm{C}_{1}$ & $15: 35$ & 5,55 & 1,35 & 1,35 & 11,1 \\
$\mathrm{Teórica}^{\mathrm{a}}$ & & $\mathbf{0 , 7 0}$ & $\mathbf{1 1 , 9}$ & $\mathbf{1 , 8 2}$ & $\mathbf{1 2 , 2}$ \\
$\mathrm{T}_{0} \mathrm{C}_{2}$ & $9: 30$ & $\mathbf{5 , 0 6}$ & $\mathbf{3 , 2 3}$ & $\mathbf{6 , 4 7}$ & $\mathbf{3 , 2 5}$ \\
$\mathrm{T}_{1} \mathrm{C}_{2}$ & $11: 35$ & 5,10 & 1,54 & 1,58 & 9,86 \\
$\mathrm{~T}_{2} \mathrm{C}_{2}$ & $13: 35$ & 5,23 & 3,04 & 1,34 & 10,9 \\
$\mathrm{~T}_{3} \mathrm{C}_{2}$ & $15: 35$ & 5,48 & 2,66 & 1,49 & 11,8 \\
$\mathrm{Teórica}^{\mathrm{a}}$ & & $\mathbf{1 , 9 7}$ & $\mathbf{1 1 1}$ & $\mathbf{1 , 7 0}$ & $\mathbf{1 5 , 2}$ \\
$\mathrm{T}_{0} \mathrm{C}_{3}$ & $9: 30$ & $\mathbf{7 , 3 2}$ & $\mathbf{5 5 , 7}$ & $\mathbf{2 , 3 2}$ & $\mathbf{1 2 , 6}$ \\
$\mathrm{T}_{1} \mathrm{C}_{3}$ & $11: 35$ & 5,49 & 6,35 & 2,53 & 10,9 \\
$\mathrm{~T}_{2} \mathrm{C}_{3}$ & $13: 35$ & 5,56 & 35,8 & 2,21 & 12,1 \\
$\mathrm{~T}_{3} \mathrm{C}_{3}$ & $15: 35$ & 5,73 & 29,4 & 2,66 & 14,3 \\
\hline
\end{tabular}

${ }^{a}$ Calculada utilizando-se as concentrações da água e do efluente (diluição)

fosfato pela mudança das condições físico-químicas e aumento da atividade iônica ${ }^{15,16}$, liberando este íon por dessorção. A adsorção a material particulado pode ter sido responsável pela diminuição da concentração de fosfato durante a preparação do efluente misto (Tabela 1). Em $\mathrm{C}_{3}(1: 1)$, é muito evidente a maior ação sinérgica do efluente, havendo uma grande liberação adicional de fosfato no sistema (Tabela 2).

O resultado das espécies nitrogenadas (Tabela 2, Fig. 3) mostra através do controle, que a coluna d'água é pobre em amônia. Nos demais experimentos, as concentrações iniciais de amônia estiveram abaixo da concentração teórica encontrada. Isto se explicaria pelo fato de termos um $\mathrm{pH}$ básico, decorrente do aporte do efluente misto $(\mathrm{pH}=12,3)$, ocorrendo perda de nitrogênio para a atmosfera, como $\mathrm{NH}_{3}$.

O sistema natural apresenta uma distribuição dos nutrientes nitrogenados compatível com processos de nitrificação, em função das concentrações de nitrato mais altas que de nitrito e amônia, com aumento ao longo do tempo, decrescendo ao final do experimento (Fig. 3). Se compararmos o comportamento do fosfato e do nitrato (Fig. 3) para o controle, podemos verificar que ambos apresentam o mesmo padrão de variação temporal. As formas nitrato e fosfato são as mais utilizadas, pelo fitoplâncton e bactérias, para a produção primária. Caso não ocorresse o decréscimo do fosfato paralelo ao do nitrato, a diminuição deste último poderia ser devido a denitrificação no sistema. Neste caso, pode ser atribuído à assimilação biológica.

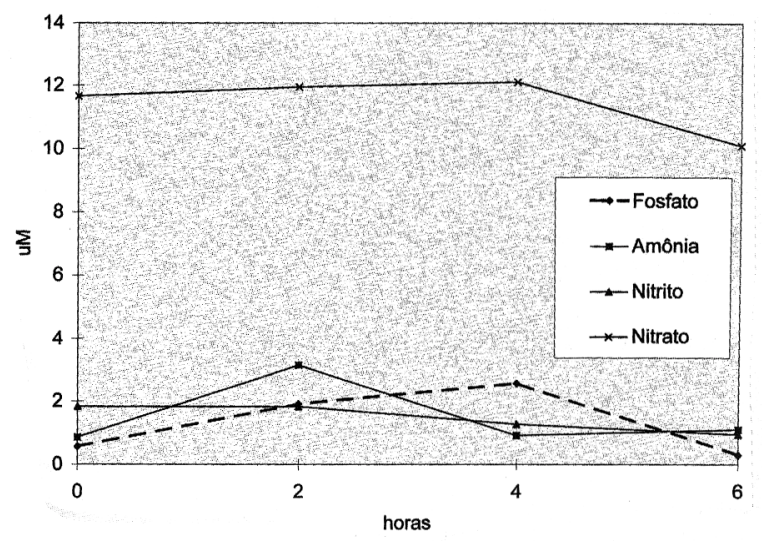

Figura 3. Variação da concentração de fosfato, amônia, nitrito e nitrato ao longo do tempo, no experimento com bolsas de polietileno (controle).

A entrada do efluente no sistema fechado, promove uma diminuição da concentração de nitrato após duas horas de incubação (Tabela 2). $O$ mesmo não ocorreu para a concentração $C_{2}$ (Tabela 2, Fig. 4). Neste experimento, a concentração inicial de nitrato foi quase 3,5 vezes inferior à calculada por diluição, enquanto a de nitrito foi proporcionalmente maior. Este comportamento pode ser atribuído à denitrificação, que no caso de $\mathrm{C}_{2}$, devido a condições ótimas, teria ocorrido quase que instantaneamente, entre o espaço de tempo de colocação do efluente nas bolsas, agitação das mesmas e obtenção das alíquotas. Este comportamento fica mais evidente quando se considera a concentração inicial do controle (sistema sem efluente, $\mathrm{T}_{0}{ }^{\prime}$ Fig. 4). Da mesma forma, este processo pode explicar a menor concentração de nitrato obtida durante o preparo do efluente composto. Considerando o tempo de montagem do experimento em cerca de 15 minutos, isto implicaria em taxas de denitrificação da ordem de $40 \mu$ moles. $h^{-1}$, relativamente altas, porém plausíveis se comparadas às obtidas por Rysgaard et al. ${ }^{17}$ (91 - $171 \mu$ moles . $\left.\mathrm{m}^{2} \cdot \mathrm{h}^{-1}\right)$. Observe-se que não houve acumulação de amônia, em consequência de perda para o ar como $\mathrm{N}_{2}, \mathrm{~N}_{2} \mathrm{O}$ (denitrificação) e $\mathrm{NH}_{3}$ (influência do $\mathrm{pH}$ no meio). A quantidade inicial de nitrato disponível, seria então superior àquelas demonstradas pelos resultados, decorrentes de parte deste ter sido assimilado para o processo de produção primária, em todas as bolsas e denitrificado nas incubações com efluente. Ao longo do tempo de incubação, verifica-se um efeito homeostático, forçando ao retorno às condições originais.

De acordo com a relação entre nitrogênio inorgânico dissolvido e fósforo inorgânico dissolvido (NID:PID), o nitrogênio foi o elemento potencialmente limitante em quase todas as incubações, exceto em $\mathrm{T}_{0} \mathrm{C}_{0}$ e $\mathrm{T}_{0} \mathrm{C}_{3}$ (Fig. 5). Em $\mathrm{T}_{0} \mathrm{C}_{0}$, obtém-se uma relação NID/PID alta em função do ambiente não ser naturalmente rico em fosfato e o mesmo não ocorrer com as formas nitrogenadas. Embora nos tempos 1 e 2 seguintes os dados sugiram uma limitação pelo nitrogênio, na realidade apenas obteve-se uma maior disponibilidade de fosfato na coluna d'água, em consequência da ausência de 
macrófitas emergentes e submersas. Quando começa a haver assimilação deste nutriente pelo fitoplâncton e bactérias esta relação aumenta. Nas outras incubações a relação NID/PID é baixa. O aporte do efluente misto no sistema, propicia a lise celular, liberando assim uma considerável quantidade de fosfato para o meio, diminuindo assim esta a relação (Fig. 5). Podemos ter uma clara idéia da relação entre a disponibilidade de nutrientes e a produção primária ao longo do experimento, observando os dados de clorofila- $a$, a disponibilidade de fosfato e a relação NID/PID (Fig. 2). O que se observa novamente é um ambiente pobre em fitoplâncton, com pouco fosfato disponível e, portanto, uma alta relação NID/PID. De acordo com o primeiro experimento (controle, Fig. 1), um ambiente pelágico com heterotrofia líquida. Nas duas horas seguintes (tempo(1), com a decomposição bacteriana e a ausência das macrófitas, haveria uma grande disponibilidade de fosfato, incrementando assim os processos fotossintéticos. Este processo diminuiria a NID/PID. Já no tempo 2, apesar da maior disponibilidade de fosfato (consequentemente uma menor NID/PID), há uma diminuição da clorofila- $a$ (Fig. 2). Isto pode ser devido a processos competitivos entre a comunidade fitoplanctônica e bacteriana ${ }^{18}$.

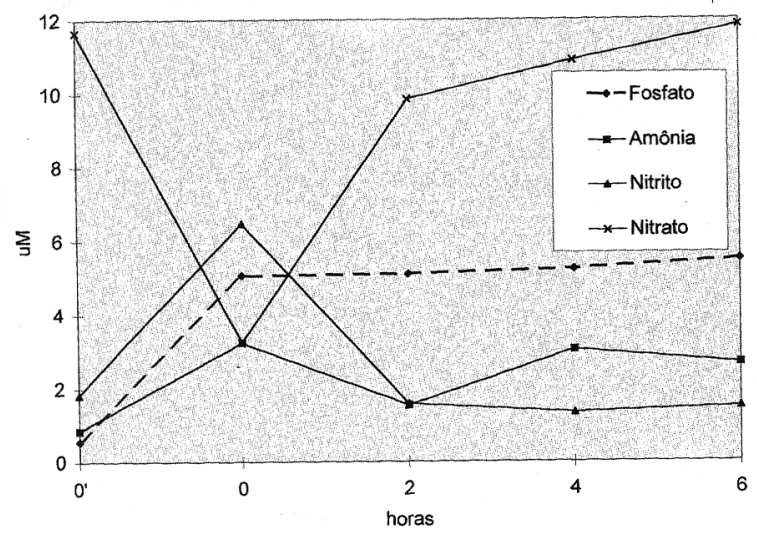

Figura 4. Variação da concentração de fosfato, amônia, nitrito e nitrato ao longo do tempo, no experimento com bolsas de polietileno $(9$ $\therefore$ 1). $T_{0^{\prime}}$ corresponde à concentração inicial sem adição de efluente.

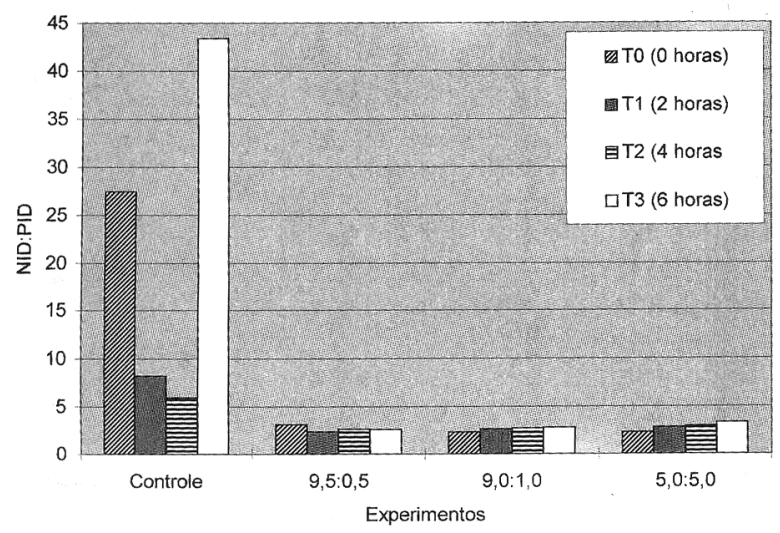

Figura 5. Variação da relação entre nitrogênio e fósforo inorgânico dissolvido (NID:PID) ao longo do experimento.

\section{CONCLUSÕES}

A entrada dos efluentes promove a eutrofização do sistema, uma vez que o ambiente pelágico do rio Piauitinga-SE, a montante do lançamento dos efluentes industriais, é naturalmente pobre em fitoplâncton, apresentando heterotrofia líquida. Este sistema aquático se baseia numa cadeia detrítica, tendo como fonte energética o material detrítico particulado proveniente das macrófitas e macroalgas. As adições de efluente nas proporções 19:1 e 9:1 promovem um incremento da produção primária líquida em função da maior disponibilidade de nutrientes no sistema. A proporção final (1:1), apesar da maior concentração de nutrientes, ultrapassa o limite de incremento da produção primária por aumento de concentração, e, devido ao concomitante aporte de matéria orgânica, propicia um retorno à condição heterotrófica líquida. No ambiente pelágico natural há uma tendência à nitrificação, porém, com a adição do efluente composto, ocorre uma inversão da tendência do sistema à nitrificação, ocorrendo denitrificação e perda de nitrogênio para a atmosfera como $\mathrm{N}_{2}, \mathrm{~N}_{2} \mathrm{O}$ e $\mathrm{NH}_{3}$. Forças homeostáticas forçam um retorno à condição anterior. A produção primária fitoplanctônica no ambiente não poluido é limitada potencialmente pelo fósforo, em virtude do consumo por macrófitas e macroalgas e abundância relativa de nitrato; nos experimentos houve limitação potencial pelo nitrogênio.

\section{AGRADECIMENTOS}

Este trabalho foi desenvolvido como monografia de bacharelado do primeiro autor, sendo parcialmente financiado por bolsa de iniciação científica cedida pelo $\mathrm{CNPq}$ (PIBIC). Agradecemos ao Dr. José do Patrocínio H. Alves (DQI/UFS), e aos Drs. Claudio A. Macedo e André M. C. de Souza (POSGRAP/UFS), pelo apoio logístico. Aos técnicos Cosme Assis, Damião Assis e João dos Santos (DBI/UFS), e aos colegas Márcio R. V. dos Santos e Everton A. dos Santos pelo auxílio no trabalho de campo. À técnica Edinalva Santos (DQI/UFS), pelo apoio no campo e laboratório.

\section{REFERÊNCIAS}

1. Odum, E. P.; Ecologia, Ed. Interamericana, Madrid. 1970.

2. Schaffer, A. Fundamentos de Ecologia e Biogeografia das Àguas Continentais. Ed. UFRGS, Porto Alegre. 1985.

3. Cid, A.; Herrero, C.; Enrique, T.; Abalde, J.; Aquatic Toxicology 1995, 31: 165.

4. Shukla, S. P.; Kumar T., A; Tiwari, D.N; Mishra, B. P.; Gupta, G. S.; Environ. Pollut. 1994, 8-4: 23.

5. Lewitus, A. J.; Kana, T. M.; Limnol. Oceanogr. 1994, 39 :182.

6. Cavalcanti, J. E. W. A.; Manual de Tratamento de Àguas Residuárias. CETESB; São Paulo 1979.

7. Silveira, E. P.; Koetz, P. R.; Ciência e Cultura 1986, 38 : 1245.

8. Rocha, A. A.; Branco, S. M.; Acta Limnol. Brasil., 1986, Vol. I :201.

9. Esteves, F. A.; Fundamentos de Limnologia. Ed. Interciência Ltda.; Rio de Janeiro. 1987; 575 p.

10. Fazzioli, I.; Química Têxtil 1980, 5 : 31.

11. Landner, L.; Blanck, H.; Heyman, U.; Lundgren, A.; Notini, M.; Rosemarin, A.; Sundelin, B.; In Chemicals in the Aquatic Environment - Advanced Hazard Assessment; Landner, L.; Ed.; Springer- Verlag; New York 1989. cap 10, p. 216-229.

12. Grasshoff, K; Ehrardt, M.; Kremling, K; Methods of Seawater Analysis; Verlag-Chemie ; Weinhein 1984; 419 p.

13. Strickland, J. D. H.; Parsons, T. R.; A Practical Handbook of Sea Water Analysis. Bulletin of the Fisheries Research Board of Canada; 122: 1-172.

14. Couto, E. C. G.; Dissertação de Mestrado; Universidade Federal Fluminense, Niterói, RJ 1989.

15. Liss, P. S. In Estuarine Chemistry; Burton, J. B; Liss, P. S.; Eds.; Academic Press; London 1976.

16. Kemp, W. M. In Estuarine Ecology, Day, J. W. et al., Eds. Wiley Interscience; New York 1989; p. 79-143.

17. Rysgaard, S.; Rysgaard-Petersen, N.; Nielsen, L. P.; Revsbech, N. P.; Appl. Environ. Microbiol. 1993, 59 :2093.

18. Howarth, R. W.; Ann. Rev. Ecol. 1988, 19 : 89. 